\title{
Zinc Halide Mediated Synthesis of 3-Amidoindoles
}

Key words

3-amidoindoles

Fischer indoles

cyclization

zinc<smiles>[R7]c1ccc(N(N)P)c(P)c1</smiles>
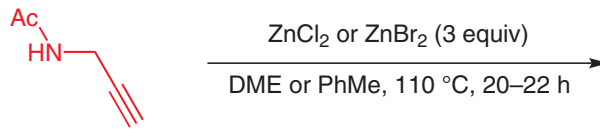

$\mathrm{R}^{1}=\mathrm{H}, i-\mathrm{Pr}, \mathrm{CN}, \mathrm{F}, \mathrm{Cl}, \mathrm{Br}, \mathrm{I}, \mathrm{SO}_{2} \mathrm{Me}$

$\mathrm{R}^{2}=\mathrm{H}, \mathrm{F}, \mathrm{Cl}$

$\mathrm{R}^{3}=\mathrm{H}, \mathrm{Me}$

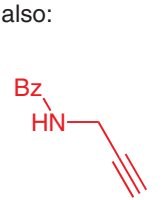

1 example $60-74 \%$ yield
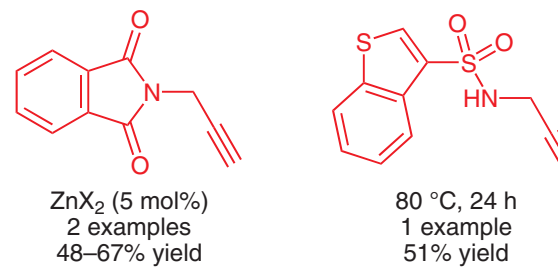<smiles>[R]c1cc([R])c2c(c1)c(NC(=O)O)c(C)n2P</smiles>

Significance: Reported is the zinc halide mediated synthesis of 3-amidoindoles through a domino alkyne amination-Fischer indole sequence. The majority of the substrate scope was performed using $\mathrm{N}$-acyl propargylamine, but examples using other $\mathrm{N}$-substituted propargylamines were shown to perform well under a subtle change of conditions. For each example two sets of conditions are shown. It is not clear whether more conditions were examined or if there was a rationale behind choosing these conditions. In contrast to the known instability of many 3-aminoindole products, the obtained compounds are reported to be crystalline stable materials which are easily handled. This process constitutes a complementary route to the synthesis of hydrazone intermediates for the Fischer indole reaction and, in view of the ready availability of alkynes, promises to find broader utility.
Comment: The 3-aminoindoles are an important class of molecules whose derivatives display a vast array of biological activity (deftly demonstrated in the excellent introduction to the current paper). Previous routes for their synthesis (such as the Fischer indole synthesis) have often been multistep and/or involved nitrogen protection/deprotection steps. The present method clearly has an advantage over previous methods as it is operationally simple, uses inexpensive and readily available starting materials, and affords the products in good to excellent yields without the need for indole $\mathrm{N}$-deprotection. The reaction has been optimized with respect to solvent, catalyst, and temperature. The substrate scope of the reaction has been moderately examined with groups that are pharmacologically interesting. These compounds showed significant inhibition of GSK-3 $\beta$, in one case as good as that of kenpaullone, a prominent GSK-3 $\beta$ inhibitor. 